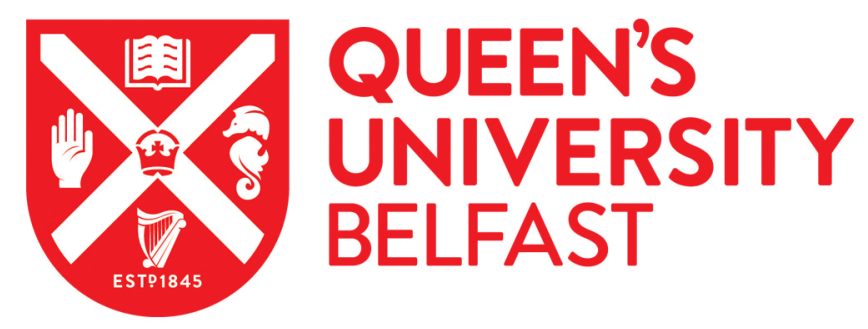

\title{
A Meta-Analysis of the Association between Appraisals of Trauma and Posttraumatic Stress in Children and Adolescents
}

\author{
Mitchell, R., Brennan, K., Curran, D., Hanna, D., \& Dyer, K. F. W. (2017). A Meta-Analysis of the Association \\ between Appraisals of Trauma and Posttraumatic Stress in Children and Adolescents. Journal of Traumatic \\ Stress. https://doi.org/10.1002/jts.22157
}

Published in:

Journal of Traumatic Stress

Document Version:

Peer reviewed version

Queen's University Belfast - Research Portal:

Link to publication record in Queen's University Belfast Research Portal

Publisher rights

(C) 2017 International Society for Traumatic Stress Studies.

This is the pre-peer reviewed version of the following article: Journal of Traumatic Stress, which has been published in final form at http://onlinelibrary.wiley.com/doi/10.1002/jts.22157/abstract This article may be used for non-commercial purposes in accordance with Wiley Terms and Conditions for Self-Archiving.

\section{General rights}

Copyright for the publications made accessible via the Queen's University Belfast Research Portal is retained by the author(s) and / or other copyright owners and it is a condition of accessing these publications that users recognise and abide by the legal requirements associated with these rights.

Take down policy

The Research Portal is Queen's institutional repository that provides access to Queen's research output. Every effort has been made to ensure that content in the Research Portal does not infringe any person's rights, or applicable UK laws. If you discover content in the Research Portal that you believe breaches copyright or violates any law, please contact openaccess@qub.ac.uk. 
Running Head: META-ANALYSIS OF TRAUMA APPRAISALS IN CHILDREN

A Meta-Analysis of the Association between Appraisals of Trauma and Posttraumatic Stress in Children and Adolescents

Ryan Mitchell, ${ }^{1}$, Kate Brennan, ${ }^{1}$, David Curran, ${ }^{1}$, Donncha Hanna, ${ }^{1}$, and Kevin F. W. Dyer ${ }^{1,2}$

${ }^{1}$ School of Psychology, Queen’s University Belfast, Belfast, Northern Ireland

${ }^{2}$ Psychological Therapies Service, Holywell Hospital, Northern HSC Trust, Antrim, Northern Ireland, BT41 2RJ k.dyer@qub.ac.uk

Author Note

Correspondence should be addressed to Ryan Mitchell, School of Psychology, The Queen’s University of Belfast, Belfast, Northern Ireland, BT9 5BN, rmitchell16@qub.ac.uk 


\begin{abstract}
Cognitive models of posttraumatic stress disorder (PTSD) place emphasis on the role of negative appraisals of traumatic events. It is suggested that the way in which the event is appraised determines the extent to which posttraumatic stress symptoms will be experienced. Therefore, a strong relationship between trauma appraisals and symptoms of PTSD might be expected. However, this relationship is not as firmly established in the child and adolescent literature, and this review aimed to address this. A systematic literature review of this relationship returned 467 publications, of which 11 met full eligibility criteria. Random effects meta-analysis revealed a large effect size for the relationship between appraisals and PTSD symptoms in children and adolescents $(r=.63,95 \%$ CI [.58 to .68], $\mathrm{Z}=17.32 ; p<$ .001), with significant heterogeneity present. Sensitivity analysis suggested that this relationship was not contingent on one specific measure of appraisals. Results were consistent with the cognitive behavioural theory of PTSD, demonstrating that appraisals of trauma are strongly related to posttraumatic stress in children and adolescents. However, this relationship was not observed in a sample of 4-6 year olds, indicating that further research is required to explicate cognitive processing of trauma in very young children.
\end{abstract}


A Meta-Analysis of the Association between Appraisals of Trauma and Posttraumatic Stress in Children and Adolescents

Posttraumatic stress disorder (PTSD) encompasses a pattern of negative psychological consequences subsequent to experiencing a traumatic event, including intrusive flashbacks, avoidance of trauma-related places/thoughts/feelings; negative alterations in cognition/mood, alterations in arousal/reactivity, and functional impairment in social/occupational domains. Epidemiological studies suggest 5\% of adolescents have met criteria for PTSD in their lifetime (Merikangas et al., 2010).

In attempting to explain how trauma may lead to PTSD, cognitive behavioural models have emphasised the role of appraisals (Ehlers \& Clark, 2000). It is suggested that the way the event is appraised, (i.e. thought about/given meaning) determines the extent to which symptoms are experienced. Using the Posttraumatic Cognitions Inventory (PTCI), several appraisal types have been shown to discriminate adults with PTSD from those without, including negative cognitions about self /world, and self-blame, (Foa, Ehlers, Clark, Tolin \& Orsillo, 1999). However, the three-appraisal structure of the PTCI was not replicated in the children’s version (CPTCI; Meiser-Stedman et al., 2009). Rather, Meiser-Stedman et al., (2009) found a two-subscale structure of Permanent and Disturbing Change and Feeble Person in a Scary World.

Both traditional and third wave cognitive theories implicate dysfunctional/unhelpful appraisals in PTSD, and predict a positive relationship between appraisals and symptoms. Multiple cross-sectional and prospective studies support this relationship in adults (Dunmore, Clark \& Ehlers, 2001), and children (Hitchcock, Ellis, Williamson \& Nixon, 2015; MeiserStedman, Dalgleish, Glucksman, Yule \& Smith, 2009; Stallard \& Smith, 2007), suggesting that appraisals correlate with posttraumatic stress (PTS), and mediate the relationship between initial/later symptoms. However, no comprehensive evaluation of the strength of the 
relationship between appraisals and PTS in children and adolescents yet exists. The present review aimed to evaluate and quantify this key theoretical pathway using meta-analysis.

\section{Method}

\section{Search Strategy}

Studies were identified by searching Web of Science, SCOPUS and Psycinfo databases, up to/including the $21^{\text {st }}$ December 2015, with the terms: (PTSD OR 'posttraumatic stress‘ OR 'posttraumatic stress’) AND (appraisal*) AND (child* OR adolescen*).

Eligible studies met the following criteria: (a) included participants aged 18 or under, (b) included quantitative measures of post-trauma appraisals and PTS, (c) included participants who had experienced at least 1 DSM-IV or 5 criterion A stressor, (d) reported a correlation between appraisals and PTS, or this info was obtainable from authors, (e) assessed PTS and appraisals more than 1 month after the traumatic event, (f) were peer reviewed, English language articles.

\section{Meta-Analytic Procedure}

MedCalc, version 16.2 was used (MedCalc Software, Ostend, Belgium) to analyze the results. In line with Hedges and Olkin (1983) $r$ values were transformed using Fisher's Z to correct for standard error skew. For presentation of results, Z values were transformed back to $r$ values. Given the variability in appraisal/PTSD measures and populations across studies, random effects meta-analysis was selected a-priori.

Heterogeneity of effect sizes was assessed via Q and $\mathrm{I}^{2}$ statistics. Q tests whether effect sizes are significantly further from the mean than would be expected via sampling error, and $\mathrm{I}^{2}$ estimates a percentage of total variance attributable to variance across studies (Macbeth \& Gumley, 2012). I $^{2}$ heterogeneity values may be interpreted as: 0-40\% (minimal), 30-60\% (moderate), 50-90\% (substantial) and 75-100\% (considerable). 
PRISMA guidelines were followed (Moher, Liberati, Tetzlaff, \& Altman, 2009). There were no missing data.

\section{Results}

\section{Selection of Studies}

There were 467 publications that were identified; 144 from Psycinfo, 177 from Web of Science, and 146 from SCOPUS. After removing duplicates, 299 articles were screened by abstract and title. From these, 245 were excluded (106 were reviews, dissertations, etc., 105 had participants over 18, 5 were qualitative, 5 were conducted within 1 month of trauma, 25 did not provide quantitative measures of PTS or appraisal of trauma/sequalae, and 3 were not in English). The remaining 50 were full-text screened, and 39 were excluded (2 were reviews, 3 featured participants without trauma exposure, 6 had participants over 18, 7 were conducted within 1 month of exposure, 14 did not measure PTS or appraisals of trauma/sequalae, 3 had data unobtainable from the paper or by request, and 4 used the same sample as another included paper.) Agreement between raters after full-text review was high $(\kappa=.80)$. Disagreement was resolved by discussion and consensus.

The final 11 studies included 4 prospective and 7 cross-sectional studies. A total of 1,578 participants were included, with studies having a mean sample size of 143.45 (SD = 119 , range $=48$ to 285 ) and participants having a weighted mean age of 12.34 (range $=4$ to 18).

*Insert Figure 1.

\section{Data Extraction and Effect Size Coding}

Sample size and correlation coefficient $(r)$ values were extracted. Three studies did not present full appraisal scale correlations with PTS. For these studies, mean full appraisal scale correlations were calculated by taking the mean of the subscale correlations, weighted by number of subscale items. Miller et al., (2012), did not present number of items in each 
subscale, so an estimated full scale correlation was calculated as the unweighted mean of the subscale correlations with PTS.

\section{Effect Size for the Relationship between Trauma Appraisals and PTSD Symptoms}

Table 1 provides information on all included studies. Untransformed effect sizes are presented, along with information on measures, participants, design, age, and gender.

For the relationship between appraisals of trauma and symptoms of PTSD, random effects meta-analysis revealed an aggregate effect size of $r=.58$, with 95\% confidence intervals between .47 and .67. $(Z=8.45 ; p<.001)$. This large effect size suggests that as trauma appraisals become more severe, so too does PTS. Heterogeneity was high $(\mathrm{Q}=84.32$; $p<.001)$, with $88.14 \%$ of the variance in effect size due to between study variance $\left(\mathrm{I}^{2}=\right.$ 88.14; 95\% CI = [80.75, 92.69]). As Figure 2 shows, all effect sizes were in the medium/large range, with the exception of Miller at al., (2012), for whom there was no significant effect. Visual inspection of a funnel plot suggested no significant publication bias.

To evaluate the influence of the distant outlier Miller et al. (2012) on the overall effect size, the analysis was rerun with this study excluded. Random effects meta-analysis revealed a large aggregate effect size of $r=.63$, (95\% CI = [.58, .68]; Z $=17.32 ; p<.001)$. Heterogeneity was in the moderate range $(\mathrm{Q}=19.53 ; p=.021)$, with $53.91 \%$ of the variance in effect size due to between study variance $\left(\mathrm{I}^{2}=53.91 ; 95 \% \mathrm{CI}=[5.87,77.43]\right)$.

\section{Sensitivity Analysis of Trauma Appraisal Measures}

The CPTCI (Meiser-Stedman et al., 2009) was the most commonly used measure of appraisals, being included in 6 of the 11 studies. Given that the CPTCI has the capability to assess appraisals of all kinds of traumata, and that it has been well- validated, the CPTCI was arguably the most appropriate measure for addressing the primary question in this review. For comprehensiveness, a decision was made to include all appraisal measures at the search 
stage. To determine whether this influenced the meta-analysis, a sensitivity analysis was conducted with the more stringent inclusion criteria of CPTCI studies only.

For the relationship between appraisals of trauma and PTSD symptoms, when only studies utilizing the CPTCI were included, meta-analysis revealed a large total effect size of $r$ $=.65,(95 \% \mathrm{CI}=[.59, .70] ; \mathrm{Z}=16.06 ; p<.001)$. Heterogeneity was moderate $(\mathrm{Q}=8.49 ; p=$ .131), with $41.08 \%$ of the variance in effect size attributable to variance between studies $\left(\mathrm{I}^{2}=\right.$ 41.08; 95\% CI $=[0.00,76.66])$. This effect size is similar to the effect size for the less stringent inclusion criteria with Miller et al. (2012) excluded, suggesting that the results are robust independent of appraisal measure.

\section{Discussion}

A strong positive association between negative appraisals of trauma and symptoms of PTS in children and adolescents was found. Despite heterogeneity in type of trauma and measures of PTS and appraisals, the effect was consistently large across studies ( $r=.45$ to .75), except for Miller et al. (2012), supporting the cognitive theory of PTSD. Crucially, this review also tentatively supports the applicability of cognitive models to children and adolescents. However, it should be noted that the CPTCI differs in factor structure from the adult PTCI. The additional factor of self-blame appraisals observed in adults but not children may reflect increased autonomy/responsibility in adulthood. Adults may be more inclined to view themselves as responsible for their circumstances, and thus deserving of blame when unwanted events occur. Nevertheless, the relationships between appraisals in general and trauma symptoms are largely equivalent in children and adults. Moreover, the emphasis on cognition found here supports the introduction of the new symptom cluster of negative alterations in cognition and mood in the DSM 5.

Regarding Miller et al. (2012), the effect size of $r=-.01$ was a distant outlier in the study. Participants in the Miller et al. study were aged 4 to 6 , with a mean of 4.96 . The 
youngest participant in any other study was 7, and the overall child mean age was 12.34 years. These very young participants may not yet have developed the cognitive capacity to make complex appraisals.

Concerning limitations, the PILOTS database was not searched, potentially overlooking other relevant studies, and the analysis was correlational, preventing casual inferences. The significant heterogeneity implicates multiple other factors across studies. However, findings are consistent with prior theory and prospective research.

In conclusion, this report is the first to summarise research on the relationship between trauma appraisals and PTS in children and adolescents, finding evidence of a strong association. By extension, these results suggest that therapies targeting appraisals may alleviate PTS in children and adolescents. 


\section{References}

Bal, S., De Bourdeaudhuij, I., Crombez, G., \& Van Oost, P. (2005). Predictors of trauma symptomatology in sexually abused adolescents: a 6-month follow-up study. Journal of Interpersonal Violence, 20 1390-405.doi10.1177/0886260503259053

Dunmore, E., Clark, D. M., \& Ehlers, A. (2001). A prospective investigation of the role of cognitive factors in persistent posttraumatic stress disorder (PTSD) after physical or sexual assault. Behaviour research and therapy, 39, 1063-1084. doi:10.1016/S0005-7967(00)00088-7

Ehlers, A., \& Clark, D. M. (2000). A cognitive model of posttraumatic stress disorder. Behaviour research and therapy, 38, 319-345. doi:10.1016/S00057967(99)00123-0

Foa, E. B., Ehlers, A., Clark, D. M., Tolin, D. F., \& Orsillo, S. M. (1999). The posttraumatic cognitions inventory (PTCI): Development and validation. Psychological assessment, 11, 303.doi:10.1037/1040-3590.11.3.303

Grych, J. H., Seid, M., \& Fincham, F. D. (1992). Assessing marital conflict from the child's perspective: The Children's Perception of Interparental Conflict Scale. Child development, 63, 558-572.doi:10.1111/j.1467-8624.1992.tb01646.x

Hedges, L. V., \& Olkin, I. (1983). Regression models in research synthesis. The American Statistician, 37, 137-140. doi:10.1080/00031305.1983.10482726

Hitchcock, C., Ellis, A. A., Williamson, P., \& Nixon, R. D. V. (2015). The Prospective Role of Cognitive Appraisals and Social Support in Predicting Children’s Posttraumatic Stress. Journal of Abnormal Child Psychology, 43, 148592.doi:10.1007/s10802-015-0034-7

Liu, S.-T., \& Chen, S.-H. (2015). A Community Study on the Relationship of Posttraumatic Cognitions to Internalizing and Externalizing Psychopathology in 
Taiwanese Children and Adolescents. Journal of Abnormal Child Psychology, 43, 1475-84.doi:10.1007/s10802-015-0030-y

Lobo, B. O. M., Brunnet, A. E., Ecker, K. K., Schaefer, L. S., Arteche, A. X., Gauer, G., \& Kristensen, C. H. (2015). Psychometric Properties of the Child Posttraumatic Cognitions Inventory in a Sample of Brazilian Children. Journal of Aggression, Maltreatment \& Trauma, 24, 863-875.doi:10.1080/10926771.2015.1043065

MacBeth, A., \& Gumley, A. (2012). Exploring compassion: A meta-analysis of the association between self-compassion and psychopathology. Clinical Psychology Review, 32, 545-552.doi:10.1016/j.cpr.2012.06.003

MedCalc Software, Ostend, Belgium

Meiser-Stedman, R., Dalgleish, T., Glucksman, E., Yule, W., \& Smith, P. (2009).

Maladaptive cognitive appraisals mediate the evolution of posttraumatic stress reactions: A 6-month follow-up of child and adolescent assault and motor vehicle accident survivors. Journal of abnormal psychology, 118, 778. doi:10.1037/a0016945

Meiser-Stedman, R., Smith, P., Bryant, R., Salmon, K., Yule, W., Dalgleish, T., \& Nixon, R. D. V. V. (2009). Development and validation of the Child Post-Traumatic Cognitions Inventory (CPTCI). Journal of Child Psychology and Psychiatry, and Allied Disciplines, 50, 432-40.doi:10.1111/j.1469-7610.2008.01995.x

Merikangas, K. R., He, J. P., Burstein, M., Swanson, S. A., Avenevoli, S., Cui, L.,...\& Swendsen, J. (2010). Lifetime prevalence of mental disorders in US adolescents: results from the National Comorbidity Survey Replication-Adolescent Supplement (NCS-A). Journal of the American Academy of Child \& Adolescent Psychiatry, 49, 980-989. doi:10.1016/j.jaac.2010.05.017 
Miller, L. E., Howell, K. H., \& Graham-Bermann, S. A. (2012). Predictors of preschoolers' appraisals of conflict in families experiencing intimate partner violence. Journal of Interpersonal Violence, 27.doi:10.1177/0886260511421675

Moher, D., Liberati, A., Tetzlaff, J., \& Altman, D.G. (2009). Preferred reporting items for systematic reviews and meta-analyses: The PRISMA statement. Annals of Internal Medicine, 151,264-269.http://dx.doi.org/10.7326/0003-4819-151-4- 20090818000135.

Nixon, R. D. V, Nehmy, T. J., Ellis, A. a., Ball, S.-A. A., Menne, A., \& McKinnon, A. C. (2010). Predictors of posttraumatic stress in children following injury: The influence of appraisals, heart rate, and morphine use. Behaviour Research and Therapy, 48, 810-5.doi:10.1016/j.brat.2010.05.002

Palosaari, E., Punamäki, R.-L., Diab, M., Qouta, S., Punamaki, R.-L. L., Diab, M., \& Qouta, S. (2013). Posttraumatic cognitions and posttraumatic stress symptoms among war-affected children: a cross-lagged analysis. Journal of Abnormal Psychology, 122, 656-61. doi:10.1037/a0033875

Ponnamperuma, T., \& Nicolson, N. A. (2016). Negative Trauma Appraisals and PTSD Symptoms in Sri Lankan Adolescents. Journal of abnormal child psychology, 44, 245-255.doi:10.1007/s10802-015-9985-y

Spaccarelli, S. (1995). Measuring abuse stress and negative cognitive appraisals in child sexual abuse: Validity data on two new scales. Journal of Abnormal Child Psychology, 23, 703-727.doi:10.1007/BF01447473

Stallard, P., \& Smith, E. (2007). Appraisals and cognitive coping styles associated with chronic post- traumatic symptoms in child road traffic accident survivors. Journal of Child Psychology and Psychiatry, 48, 194-201. doi:10.1111/j.14697610.2006.01692.x 


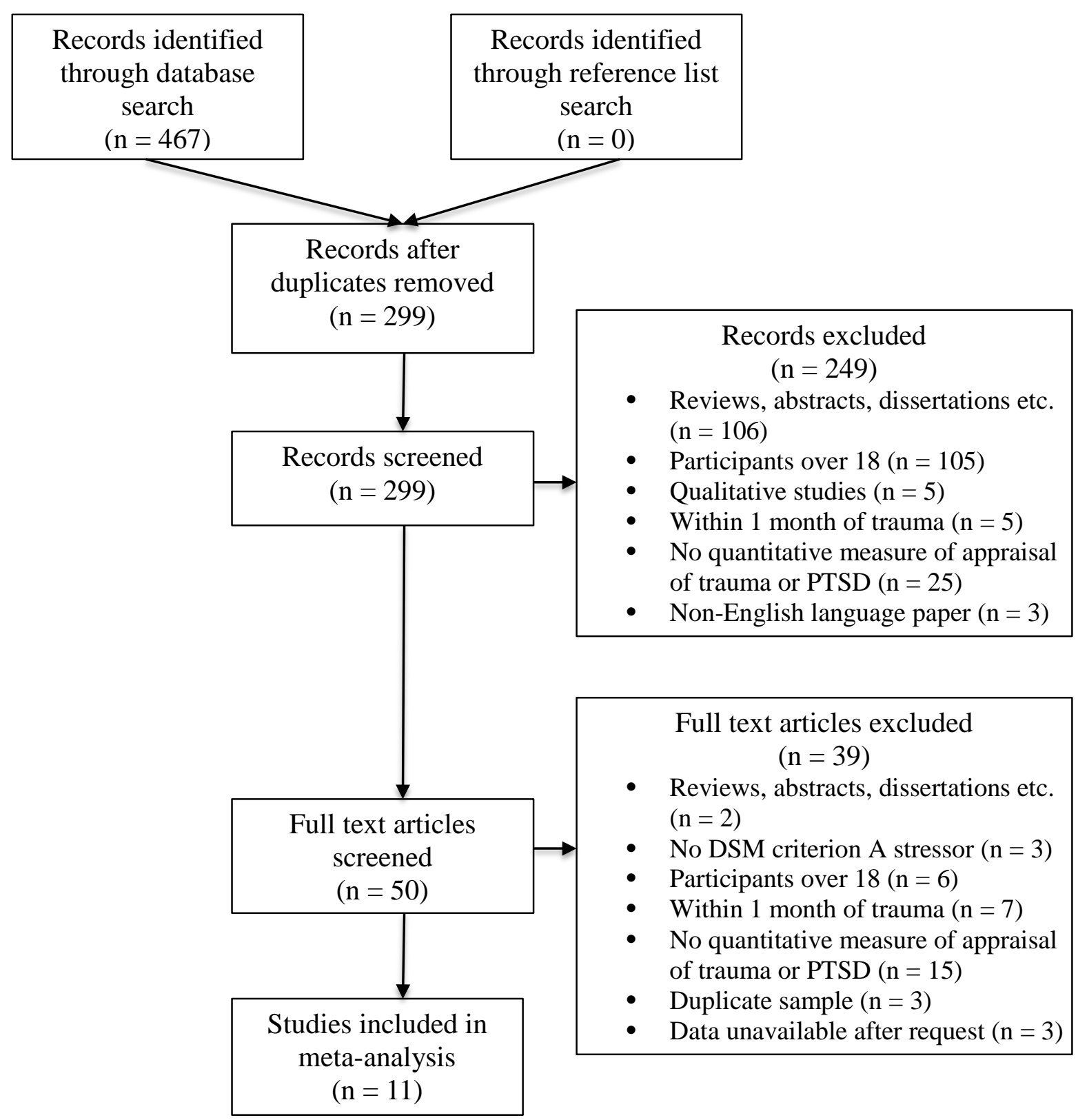

Figure 1: Summary of Search 
Bal et al., 2005

Hitchcock et al., 2015

Lobo et al., 2015

Meiser-Stedman et al., 2009

Miller et al., 2012

Nixon et al., 2010

Palosaari et al., 2013

Ponnamperuma et al., 2015

Liu \& Chen, 2015

Spaccarelli, 1995

Stallard \& Smith, 2007

Total (random effects)
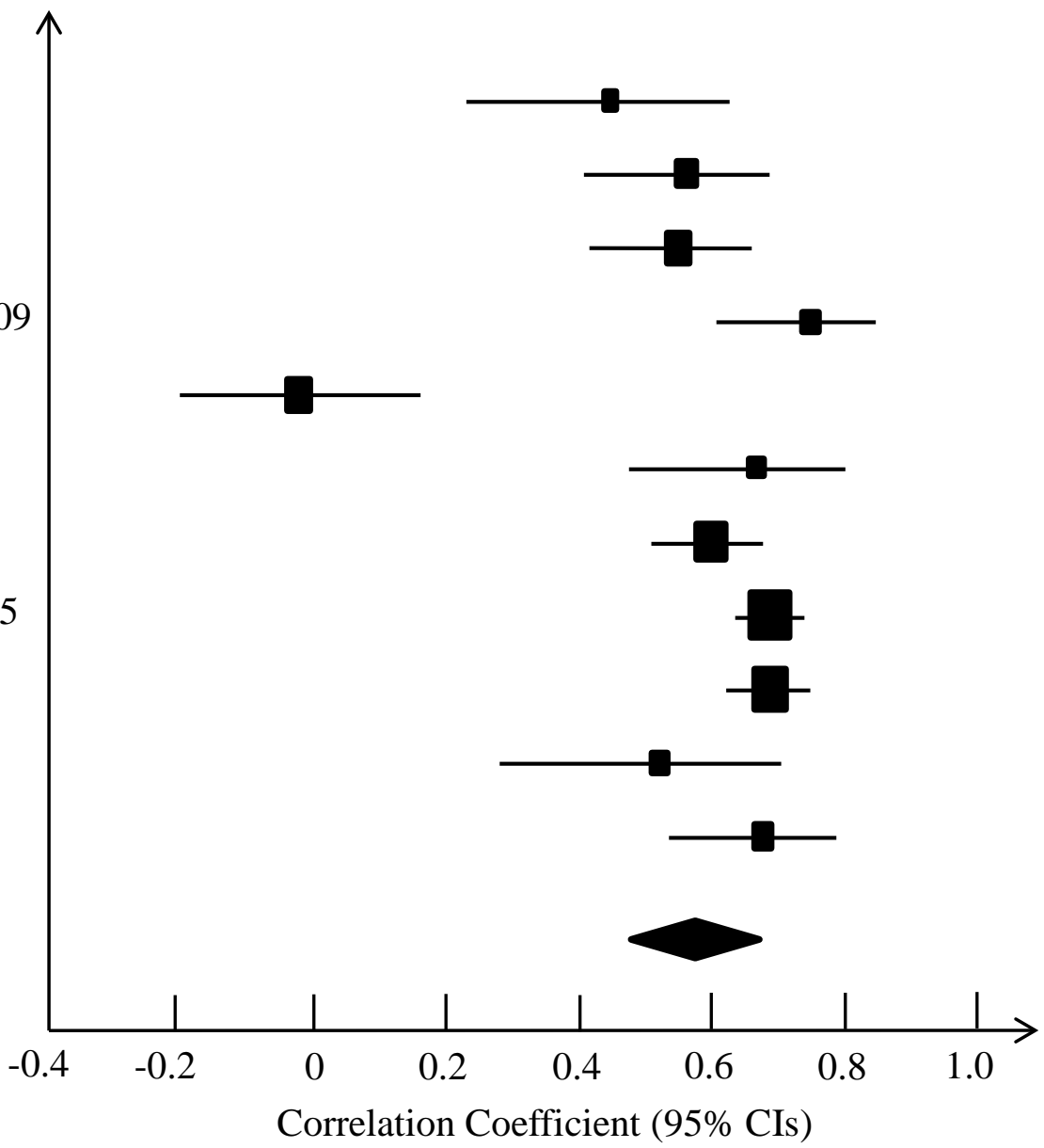

Figure 2: Trauma Appraisals and PTSD Symptoms by Study 
Table 1.

Summary of Included Studies

\begin{tabular}{|c|c|c|c|c|c|c|c|c|}
\hline Study & $n$ & Measure PTSD & $\begin{array}{l}\text { Measure } \\
\text { Appraisal }\end{array}$ & Participants & Design & Mean age & $\begin{array}{l}\text { Gender } \\
\text { ratio }\end{array}$ & Full scale $r$ \\
\hline & & & & & & & & Mean $=.562$ \\
\hline Liu \& Chen, & 285 & Chinese UCLA PTSD & Chinese & Students & Cross- & $13.5(2.7)$ & $43.9 \% \mathrm{M}$ & .69 \\
\hline (2015) & & index & CРTCI & (trauma & sectional & $9-17$ & & \\
\hline (2015) & & & & youth & sectional & $7-17$ & & \\
\hline Meiser-Stedman & 59 & CRIES & CPTCI & Experienced or & Cross- & $14(1.8)$ & N/A & .75 \\
\hline et al, (2009) & & & & witnessed & sectional & N/A & & \\
\hline
\end{tabular}




\begin{tabular}{|c|c|c|c|c|c|c|c|c|}
\hline \multirow[b]{2}{*}{ Miller et al, } & \multirow[b]{2}{*}{116} & \multirow[b]{2}{*}{ PTSD Semi-Structured } & \multirow[b]{2}{*}{ CPIC } & $\begin{array}{l}\text { assault/road } \\
\text { accident }\end{array}$ & & \multirow[b]{2}{*}{$4.96(.87)$} & \multirow[b]{2}{*}{$51.7 \% \mathrm{M}$} & \multirow[b]{2}{*}{-.01} \\
\hline & & & & Witnessed & Cross- & & & \\
\hline \multirow[t]{5}{*}{ (2012) } & & Interview and & & parental & sectional & $4-6$ & & \\
\hline & & Observational Record for & & intimate partner & & & & \\
\hline & & Infants and Young & & violence & & & & \\
\hline & & Children (Scheeringa \& & & & & & & \\
\hline & & Zeanah, 1994) & & & & & & \\
\hline Nixon et al, & 48 & CPSS & CPTCI & Potentially & Prospective & $11.8(2.67)$ & $68.7 \%$ & .67 \\
\hline (2010) & & & & traumatic event & & $7-17$ & M & \\
\hline Palosaari et al, & 240 & CIES Arabic & СРТCI & War trauma & Prospective & $11.35(0.57)$ & N/A & .60 (SEM \\
\hline (2013) & & & Arabic & & & $10-12$ & & standardized \\
\hline & & & & & & & & estimate) \\
\hline Ponnamperuma & 414 & UCLA PSTD-RI & Adapted & Tsunami & Cross- & 13.6 & $54.3 \% \mathrm{~F}$ & .69 \\
\hline et al, (2015) & & & Stallard & & sectional & $12-16$ & & \\
\hline
\end{tabular}


Smith (2007)

measure

\begin{tabular}{|c|c|c|c|c|c|c|c|}
\hline Spaccarelli, & 48 & Some TSCC items and & NASAS & Sexual abuse & Cross- & $11-18$ & \multirow[t]{3}{*}{$100 \% \mathrm{~F}$} \\
\hline \multirow[t]{2}{*}{ (1995) } & & some from Horowitz & & & sectional & median 14 & \\
\hline & & (1979) & & & & & \\
\hline Stallard \& & 75 & CAPS-C & Own & Road accident & Cross- & $14.01(3.36)$ & $50.7 \% \mathrm{~F}$ \\
\hline Smith, (2007) & & & Measure & & sectional & & \\
\hline
\end{tabular}

